\title{
A URbanizaÇão ILIMITAda E O FUTURO dA CIDADE
}

Unlimited urbanization and the future of the city

\author{
Regina M. Prosperi Meyer \\ Universidade de São Paulo FAU-USP, Brasil \\ reginameyer@uol.com.br
}

RESUMO: $\mathrm{O}$ artigo aborda aspectos da inerente relação que há entre o padrão de urbanização contemporâneo, designado como ilimitado, e a cidade consolidada. A designação cidade compreende neste texto todas as escalas e hierarquias das organizações urbanas, sobretudo as metropolitanas e macro-metropolitanas. Comparado ao padrão de desenvolvimento do processo de urbanização que prevaleceu no período de metropolização — a conurbaçãoo processo atual não se dá através de agregação de núcleos urbanos existentes, mas simplesmente expande-se sobre um território ainda disponível. Sendo que o aspecto mais marcante desta mudança é a inversão de orientação entre as duas formas de urbanização, enquanto a primeira era centrífuga, isto é, da cidade para fora dela, a segunda é centrípeta, dos territórios urbanizados para a cidade consolidada. Tal inversão acaba por produzir uma profunda desorganização nos espaços intraurbanos consolidados. A expressão "a cidade está em toda parte" acaba por sintetizar com clareza o território produzido pela urbanização ilimitada. $\mathrm{O}$ artigo busca ainda, através de um retrospecto de abordagens pioneiras das atribuições e possibilidades de ações propostas por disciplinas relacionadas ao planejamento urbano, avaliar as alternativas que se apresentam para que ambos possam atuar diante da urbanização contemporânea.

PalaVras CHAVE: urbanização contemporânea, cidade, organização urbana, metropolização, padrão de desenvolvimento.

RESUM: L'article aborda aspectes de la relació inherent entre el patró d'urbanització contemporània, designat com a il-limitat, i la ciutat consolidada. El nom ciutat inclou en aquest text totes les escales i jerarquies de les organit- 
zacions urbanes, especialment les metropolitanes i macro-metropolitanes. La suposició que impulsa l'article és que el procés d'urbanització actual descrit per moltes paraules i conceptes ha d'entendre's com a il-limitat i que els seus nous atributs físics, espacials i estructurals estan canviant les seues relacions amb la ciutat consolidada. En comparació amb el patró de desenvolupament del procés d'urbanització que va prevaldre en el període de metropolització, la conurbació, el procés real no té lloc mitjançant l'agregació dels centres urbans existents, simplement s'expandeix sobre un territori encara disponible. L'aspecte més cridaner d'aquest canvi és la inversió d'orientació entre les dues formes d'urbanització, mentre que la primera era centrífuga, és a dir, des de la ciutat cap a l'exterior, la segona és centrípeta, des dels territoris urbanitzats fins a la ciutat consolidada. Tal inversió acaba produint una profunda desorganització en els espais intraurbans consolidats. L'expressió «la ciutat està a tot arreu» resumeix clarament el territori produït per la urbanització il·limitada. A través d'una retrospectiva d'enfocaments pioners de les atribucions i possibilitats d'accions proposades per les disciplines relacionades amb la planificació urbana, l'article també busca avaluar les alternatives que es presenten perquè tots dos puguen actuar enfront de la urbanització contemporània.

Paraules clau: urbanització contemporània, ciutat, organització urbana, metropolització, patró de desenvolupament.

RESUMEN: El artículo aborda aspectos de la relación inherente entre el patrón de urbanización contemporánea, designado como ilimitado, y la ciudad consolidada. El nombre ciudad incluye en este texto todas las escalas y jerarquías de las organizaciones urbanas, especialmente las metropolitanas y macro-metropolitanas. La suposición que impulsa el artículo es que el proceso de urbanización actual descrito por muchas palabras y conceptos debe entenderse como ilimitado y que sus nuevos atributos físicos, espaciales y estructurales están cambiando sus relaciones con la ciudad consolidada. En comparación con el patrón de desarrollo del proceso de urbanización que prevaleció en el período de metropolización, la conurbación, el proceso real no tiene lugar mediante la agregación de los centros urbanos existentes, simplemente se expande sobre un territorio aún disponible. El aspecto más llamativo de este cambio es la inversión de orientación entre las dos formas de urbanización, mientras que la primera era centrífuga, es decir, desde la ciudad 
hacia el exterior, la segunda es centrípeta, desde los territorios urbanizados hasta la ciudad consolidada. Tal inversión termina produciendo una profunda desorganización en los espacios intraurbanos consolidados. La expresión «la ciudad está en todas partes» resume claramente el territorio producido por la urbanización ilimitada. A través de una retrospectiva de enfoques pioneros de las atribuciones y posibilidades de acciones propuestas por las disciplinas relacionadas con la planificación urbana, el artículo también busca evaluar las alternativas que se presentan para que ambos puedan actuar frente a la urbanización contemporánea.

Palabras clave: urbanización contemporánea, ciudad, organización urbana, metropolización, patrón de desarrollo.

ABSTRACT: The article addresses aspects of the inherent relationship between the pattern of contemporary urbanization, designated as unlimited, and the consolidated city. The name city includes in this text all the scales and hierarchies of urban organizations, especially the metropolitan and macro-metropolitan ones. The assumption that drives the article is that the current urbanization process described by many words and concepts must be understood as unlimited and that its new physical, spatial and structural attributes are changing its relations with the consolidated city. Compared to the pattern of development of the urbanization process that prevailed in the metropolization period - the conurbation - the actual process does not take place through the aggregation of existing urban centers, it simply expands over a territory still available. The most striking aspect of this change is the reversal of orientation between the two forms of urbanization, while the first centrifugal era, that is, from the city to outside of it, the second is centripetal, from the urbanized territories to the consolidated city. Such inversion ends up producing a profound disorganization in the consolidated intraurban spaces. The expression "the city is everywhere" clearly summarizes the territory produced by unlimited urbanization. Through a retrospective of pioneering approaches to the attributions and possibilities of actions proposed by the urban planning related disciplines, the article also seeks to evaluate the alternatives that are presented so that both can act in the face of contemporary urbanization.

KEYWORDS: contemporary urbanization, city, urban organization, metropolization, development pattern. 
Da vivência das cidades nasceu uma vivência do futuro.

Raymond Williams, 1975

Não tente rapidamente encontrar uma definição de cidade; é muito grande, existe grande possibilidade de se enganar.

George Perec, 2000

\section{O lugar da cidade ${ }^{1}$ ante a urbanização total}

$\Lambda_{\text {põem a pensar o assunto, sobretudo de maneira especulativa, a enfren- }}^{\text {s reflexões acerca da cidade do futuro costumam levar todos que se pro- }}$ tar uma forte polaridade. De um lado estão aqueles que a concebem a partir de uma visão utópica, guiada pela ambição de ver superado os mais desafiantes problemas da atualidade. Na outra ponta, ficam aqueles que prefiguram uma cidade distópica e, da mesma forma, também conduzida pelos problemas e desafios do presente; só que nesse caso sem o compromisso direto com as suas superações. A estratégia, no caso do olhar distópico é apresentar os problemas urbanos de forma radical. Domina a cena da cidade distópica aspectos sombrios, ameaçadores, adversos ao bem-estar material e psicológico dos seus habitantes. Como uma antítese da utopia, a distopia urbana coloca ênfase nos conteúdos que confirmam a degradação urbana e a desordem social, mostrados através do ambiente urbano e do comportamento de seus habitantes. Um aspecto interessante da construção desta polaridade entre as duas prefigurações é que nos dois casos a realidade imediata, isto é, a realidade da cidade do presente é o ingrediente primordial para a construção das duas visões do futuro da cidade. Ambas se apoiam numa realidade urbana bem definida, verossímil e, o que é muito importante, familiar para aqueles a quem se dirigem as duas hipóteses. É justamente desta capacidade de ter diante dos olhos aspectos da realidade com a qual se convive, deformados para uma ou outra pre-configuração, que reside a força das ideias-imagem que as descrevem.

1. A palavra cidade é utilizada nesse texto de forma abrangente, incluindo toda hierarquia e formas de organização, sobretudo a metropolitana. 
Contrapostas, estas duas abordagens costumam frequentar os discursos sobre a cidade do futuro. Questões sociais, econômicas, culturais podem encaminhar as reflexões sobre o futuro urbano tanto para uma visão utópica ou distópica. Ameaçadores ou benévolos os argumentos e suas correspondentes representações imagéticas, apontam, contudo, para uma convergência: a cidade permanecerá nas duas hipóteses como uma entidade exclusivamente urbana e, o que será mais decisivo, inserida em um processo de urbanização difusa. Será, portanto, a partir deste padrão que se nutrirão as promessas utópicas de cidades do futuro regidas por equilíbrio e beleza ou, pela presença de crescente desordem e decadência antecipadas pelo olhar distópico. Sendo que o crescimento urbano - cerceado no caso da cidade utópica, ou descontrolado no caso da distópica - continuará a servir como referência para as duas vertentes. E esta é uma perspectiva central para o tema aqui abordado.

A hipótese apresentada por Henri Lefébvre nos anos 60, segundo a qual o planeta tendia para a urbanização total se mostrou correta (Lefébvre,1999). Vale lembrar que a urbanização é o processo de transformação de uma sociedade, região ou território de rural para urbano, ou seja, não representa somente o crescimento da população das cidades, mas o aumento desta em relação aos habitantes do campo. Portanto, quando a população urbana de um determinado local cresce em número maior que a do campo ocorre um processo de urbanização. Efetivamente, no ano de 2009 a Agência ONU-Habitat anunciou que pela primeira vez na história a população mundial já era predominantemente urbana: mais de 3,7 bilhões de pessoas viviam em cidades. É preciso lembrar que a previsão para que tal fato ocorresse, segundo a mesma agência, seria o ano de 2030. A antecipação atestou uma aceleração do processo de urbanização que passou a servir como informação adicional quando se analisa os dados para a interpretação e o encaminhamento do futuro urbano. A previsão atual da ONU-Habitat é que até 2030 o conjunto das cidades de todo planeta receberá mais 60 milhões de pessoas. Sem buscar aqui aprofundar um assunto especializado de demografia urbana, fica claro, portanto, que a questão se tornou um aspecto inexorável para pensarmos o futuro da organização urbana e, consequentemente, o lugar da cidade nesse cenário. 


\section{A cidade do futuro não será uma criação ex-novo}

A partir da observação direta e coleta de dados dos diferentes territórios urbanos contemporâneos sejam eles asiáticos, africanos, americanos ou europeus, será possível estabelecer hipóteses para a cidade do futuro. E, para pensa-la o ponto de partida será, como dissemos acima, a cidade real, para entender o que existe de mais universal e genérico nas cidades do presente, assim como, das relações intrínsecas que existem entre cidades e processos de urbanização e de transformação que lhes são inerentes. Nosso primeiro ponto é reconhecer que a cidade do futuro independentemente de sua localização global, não será uma entidade inteiramente nova, produzida ex-novo. A cidade do futuro, distinta desta na qual vivemos nesta segunda década do século XXI, que enfrenta e assimila as mudanças introduzidas pela revolução tecnológica e científica da denominada Quarta Revolução Industrial, será a matéria prima essencial tanto para a reflexão como para as propostas urbanísticas e de planejamento urbano que serão produzidas e realizadas.

Durante a história da cidade, precisamente na passagem da organização urbana medieval para a renascentista, quando foi estabelecida a transição da cidade enquanto aparato defensivo e essencialmente econômico, transformando-se num novo organismo que assimilava e incluía as dimensões sociais, políticas e técnicas do fim do feudalismo, houve uma passagem tão revolucionária quanto essa que vivemos hoje. A cidade ideal dos humanistas e dos príncipes florentinos do século Xv baseou-se em um forte sentido de consciência cívica que vinha das comunas livres de organização política e social inerente à cidade estado italiana. O legado da polis grega esteve sem dúvida no centro daquela enorme transformação. E, a cidade enquanto organização inerentemente físico-espacial, contendo atributos políticos, sociais e culturais, baseada nas sempre renovadas possibilidades técnicas, passou a ser objeto de pensamento e de ação. Nascia assim um conceito central para o urbanismo: admitir e assimilar a cidade como objeto de projeto, contando para isso com a reflexão e a prática de profissionais liberais especializados que detinham os meios para essa ação (Argan, 1992).

Cabe perguntar diante desta observação em que medida a cidade ideal do renascimento, elaborada conceitualmente em pleno século Xv, num contexto histórico que antecedeu a primeira etapa da industrialização capitalista, 
pode conter algum aspecto passível de servir de paralelo com a cidade destas primeiras décadas do século XxI, já classificada como pós-industrial. Nesse raciocínio está implícito a permanência das questões que a cidade industrial enfrentou entre os séculos XVII e XIX, durante o processo de industrialização. Uma possível resposta se relaciona às evidências que indicam que a cidade com a qual teremos que lidar no século XXI, vive uma situação igualmente revolucionária, sobretudo em vista a entrada disruptiva de novas tecnologias que presidem a Quarta Revolução Industrial. As distinções entre as duas situações são óbvias, mas algumas analogias ainda subsistem. Uma delas é a necessidade de acompanhar e entender as transformações permanentes, buscando estabelecer novos conceitos, práticas e instrumentos para honrar o compromisso e a possibilidade de enfrentar a cidade como objeto de projeto. Neste contexto o historiador da arquitetura Giulio Carlo Argan oferece uma reflexão valiosa para que tal compromisso possa ser mantido diante da cidade do presente na sua relação com a cidade do futuro quando escreve: «[...] sempre existe uma cidade ideal dentro ou sob a cidade real, distinta desta como o mundo do pensamento o é do mundo dos fatos (Argan, 1992, p. 73)».

A afirmação pode parecer desencorajadora, pois aponta para a frustração do urbanismo enquanto pensamento e ação de promover cidades com mais qualidade a partir de projetos, ao afirmar que os fatos inerentes ao desenvolvimento urbano são mais decisivos do que qualquer objetivo aspirado pelos projetos que se pretendeu introduzir. No entanto, Argan, generosamente, nos oferece um caminho. Ao considerar que mesmo sendo sobrepujados por fatos que encobrem os trechos de cidade associados a antigos projetos qualificadores, estes poderão ser reconhecidos, recuperados e se tornarem eles mesmos novas referências para a cidade do futuro (Argan, 1992, p. 75). Seu entendimento de que a cidade enquanto processo construtivo não é gestalt (forma), mas gestaltung (forma em construção) (Argan, 1992, p. 75), isto é, uma entidade virtualmente aberta e passível de receber projetos de intervenção ao longo de sua história, abre a possibilidade de intervenções permanentes. O projeto urbanístico coloca-se assim numa trincheira de combate contra os fatos, quase sempre ditados por interesses econômicos, que podem arruinar uma organização urbana considerada melhor para a sociedade. 
A estas considerações de Argan se somou de forma pragmática o conceito e o método de trabalho conhecido como intervenção na cidade existente, tal como foi proposto pelo arquiteto urbanista português Nuno Portas no início dos anos 1970. A elaboração feita por Portas tornou-se um marco teórico e empírico para pensar e, sobretudo, entender e projetar os processos de transformação urbana visando a preservação do passado histórico ao realizar os projetos que garantissem o futuro da cidade, isto é, a cidade do futuro. Nas suas próprias palavras:

Por intervenção na cidade existente entendemos o conjunto de programas e projetos públicos ou de iniciativas autónomas que incidem sobre os tecidos urbanizados dos aglomerados, sejam antigos ou relativamente recentes, tendo em vista: a sua reestruturação ou revitalização funcional (atividades e redes de serviços); a sua recuperação ou reabilitação arquitetônica (edificação e espaços não construídos, designadamente os de uso público); finalmente, a sua reapropriação social e cultural (grupos sociais que habitam ou trabalham em tais estruturas, relações de propriedade e troca, atuações no âmbito da segurança social. (Portas, 1969)

Voltaremos a este conceito proposto por Portas na parte final deste artigo. O importante por enquanto é que tal abordagem ganhou importância suplementar por ter sido elaborada numa conjuntura histórica em que o urbanismo já havia se distanciado, de forma bastante crítica, das proposições que viam as grandes cidades e metrópoles industrias como exemplos de "cidades velhas"; aquelas que foram definidas por Frank Lloyd Wright como cidades sem nenhuma qualidade. No livro que apresenta seu conceito e proposta da cidade do futuro - "The Broadacre City" - ele avalia que as potentes metrópoles americanas, não tem qualquer possibilidade de servir como ponto de partida para pensar e realizar a cidade do futuro (Wright, 1970). Tanto Wright como Le Corbusier, estavam convictos da necessidade de afastar a herança urbana que resultou de desastrosos processos de industrialização muito intensos e rápidos em metrópoles e cidades industriais. Apoiados nos pressupostos da tabula rasa, visavam a criação de uma nova ordem urbana da qual seriam eliminados os problemas urbanos oriundos do processo de industrialização através de propostas ex-novo. Pois tanto a semi-agrária e ultra individualista living-city de Wright quanto a ordenada cité radieuse de Le Corbusier rejeitavam de forma categórica a cidade real, ou seja, a cidade histórica. 
As simplificações racionalistas, funcionais e formais da complexa organização urbana que prevaleceu ao longo de pelo menos 40 anos -- entre o final dos anos 20 e o início dos anos 60 -- acabou por se mostrar imprópria para os projetos de intervenção e, sobretudo, de proposições ex-novo. As grandes cidades, sobretudo as metrópoles industriais, principais agentes do desenvolvimento capitalista, mostraram-se avessas à intervenção nos processos de expansão territorial. A lógica de planos controladores e ordenadores das funções urbanas encontrou obstáculos terminantes. Pois, além de dispensar os aspectos essenciais da construção histórica das cidades, as proposições se mostraram incapazes de vencer as exigências fundamentais do próprio capitalismo industrial. É um fato, a ser sublinhado, que premissas contidas nas propostas de Wright e Le Corbusier acabaram migrando para a teoria e os métodos do nascente planejamento urbano, produzindo resultados também pouco louváveis.

Ficou patente a dificuldade em assimilar os conceitos relativos ao crescimento urbano e, acima de tudo, os instrumentos utilizados para limita-lo, tanto do ponto de vista populacional como territorial. Desta forma, após décadas de trabalho intenso, organizado com grandes equipes multidisciplinares, preocupadas em inovar abordagens, assistimos nas duas últimas décadas do século $\mathrm{Xx}$, ao triunfo do crescimento físico e populacional das cidades, sobretudo das metrópoles, derrotando a enorme gama de instrumentos técnicos voltados para a moderação do processo de urbanização e, sobretudo, de ordenação de uso e ocupação do solo. O impasse ficou evidente e ganhou muitas reflexões.

Tafuri (1985, p.81) faz uma análise bastante decisiva da relação entre as metrópoles industriais e as formas assumidas pelo urbanismo e pelo planejamento urbano. No capítulo "Arquitetura radical e cidade", Tafuri percorre as experiências exemplares dos modelos de desenvolvimento urbano da primeira metade do século xx, para finalizar apontando a natureza "quase sempre inegociável" e violenta dos processos de urbanização que não permitiram lograr respostas positivas à altura do esforço intelectual, instrumental e técnico empregados por arquitetos urbanistas de importância indiscutível. Sua interpretação das obras fundamentais do período é muito certeira:

A Frankfurt planejada de Ernst May, a Berlim administrativa de Martin Wagner, a Hamburgo de Fritz Schumacher, a Amsterdam de Cor van Eesteren, 
são os capítulos mais importantes da gestão social-democrata da cidade. Mas, lado a lado como dois oásis de ordem das Siedlungen - verdadeiras utopias construídas, à margem de uma realidade urbana por elas bem pouco condicionada - as cidades históricas e os territórios produtivos continuam a acumular e a multiplicar as suas contradições. E são em grande parte contradições que bem depressa se revelarão mais decisivas dos instrumentos elaborados pela cultura arquitetônica numa tentativa para as controlar. (Tafuri, 1985, p. 81).

Neste sentido, é preciso lembrar o quanto regulamentações urbanísticas contidas em planos normativos que buscaram evitar desvios e ameaças aos pontos de doutrina estabelecidos nos CIAM, visando à realização dos almejados cenários modernistas, se tornaram, em grande medida, responsáveis pelas características assumidas pelas metrópoles industriais. Para Tafuri, a constatação das limitações das ações de controle, revelando a fragilidade da denominada «ideologia da ordem», desafiaram o pensamento e a prática do planejamento urbano (Tafuri, 1985, p. 81). Os conflitos resultantes dos planos urbanos de perfil normativo e ordenador que nasceram justamente do embate entre as legislações criadas com o objetivo de controlar o crescimento urbano e as lógicas inerentes aos processos econômicos regidos pela economia de mercado, tornaram-se recorrentes. A ausência de instrumentos de ação capazes de permitir a negociação entre os postulados funcionalistas do planejamento urbano e o modelo econômico vigente, geraram, na visão de Tafuri, problemas urbanos bastante específicos. As soluções e encaminhamentos ad hoc, quase sempre conjunturais e assistemáticos, buscando acomodar as diversas dimensões do processo - de um lado a teoria urbanística e, do outro, as relações econômicas e sociais que atuam nas cidades - mostraram-se incapazes de produzir modelos eficientes para conduzir o desenvolvimento urbano.

Uma importante contribuição a essa discussão veio em 1976, de outro contexto acadêmico e intelectual, através do economista americano Harvey Molotch que abordou a questão do impulso permanente da urbanização, apoiado em dados e métodos próprios à economia urbana, e produziu a teoria da «cidade como máquina de crescimento» (Molotch, 1976). Este conceito se tornou bastante influente por ter descrito de forma objetiva um elemento central para a compreensão das dificuldades nas quais estavam envolvidos 
o urbanismo e o planejamento urbano voltados à regulação e controle do crescimento urbano. Identificando o fortalecimento de uma nova classe econômica composta pelos rentiers urbanos (Jonas and Wilson, 1999, p. 5-6, 12) que atuavam no universo das grandes metrópoles americanas através da rentabilidade de investimentos imobiliários, Molotch estabeleceu uma rede de relações internas ao próprio desenvolvimento urbano que estimulam um permanente impulso para o crescimento urbano (Jonas and Wilson, 1999, p. 247).

\section{Coketown está hoje em toda parte}

Apesar de uma evidente dificuldade para encontrar novos métodos de trabalho, os órgãos públicos cuja função precípua é o controle das formas e do ritmo do crescimento urbano, buscaram renovar suas ações. A partir da elaboração de planos de desenvolvimento nos quais faltava uma reflexão mais consistente acerca dos obstáculos encontrados na consecução das suas propostas, encontraram, no entanto, um caminho de renovação a partir da produção de regras e normas menos rígidas. Assim é que a partir dos anos 80, numa espécie de fuga para frente, as denominadas questões urbanas passaram a ser tratadas através de abordagens menos prescritivas, mostrando-se mais mediadoras de interesses e de conflitos. A presença dos processos de transformação urbana muito rápidos, profundos e contínuos, situados tanto no interior das cidades como nos seus espaços periféricos, gerou incontáveis modelos de atuação, sendo que todos passaram a reivindicar o qualificativo de planos de ações estratégicas. Dentre vários aspectos o que distinguia as novas abordagens dos modelos clássicos de planejamento do passado era a disposição de garantir de forma dinâmica a assimilação constante de informações, dados e, mais recentemente das novas e intensas mudanças no modo de produção que se apresentaram gradualmente a partir da década de 80 .

A nova postura recebeu criticas contundentes de várias frentes que enxergaram corretamente uma intensa liberalidade no tratamento dos problemas urbanos. Um laissez-faire urbano mascarado pelo discurso técnico. Inúmeros estudos colocaram em xeque as formulações que visavam acomodar os problemas e os interesses econômicos dentro de soluções que não se mostraram 
asseguradas suficientemente para equacionar o essencial da vida urbana. A necessidade de deixar brechas para assimilar mudanças de cenário e, sobretudo aquelas que vinham da tecnologia da informação e da comunicação, tornou-se uma marca do planejamento estratégico, fragilizando as decisões pactuadas na sociedade em função de pressões econômicas.

Enquanto a discussão em torno do modelo estratégico prosseguia e, em meio às tentativas para encontrar modelos bens sucedidos, as tais "boas práticas" do denegrido planejamento estratégico, o Relatório «Slums of the World» da ONU-Habitat (DPU-UCL and UN Programme of Human Settlements, 2003) revelou um cenário urbano desalentador cujo foco era pobreza urbana situada, sobretudo, no denominado Terceiro Mundo. O que se lê no documento oficial não é apenas a descrição de um conjunto de problemas vinculados ao processo de urbanização, já assumido como fora de controle, mas sobretudo, a descrição de novas características físicas e funcionais adquiridas pela escala da expansão urbana. No seu livro "Planeta Favela" (Davis, 2006) apoiado nos relatórios da ONU-Habitat, além de extensa e específica bibliografia, expõe com muitos dados e interpretações o panorama urbano das favelas situadas nas metrópoles e cidades do denominado Terceiro Mundo. Embora as questões urbanas relacionadas ao processo de favelização não fossem novas, a nova escala e o ritmo do processo, transformaram a favelização planetária num problema a ser enfrentado com novos instrumentos de ação. Hoje, já não é mais possível enfrentar a presença de favelas intraurbanas com projetos pontuais, realizados em outras circunstâncias históricas, ainda bem recentes, quando a produção dos conjuntos habitacionais de perfil modernista, situados tanto no interior das cidades como fora delas, era considerada uma política publica habitacional apropriada. A proporção e a consolidação dos imensos territórios ocupados por favelas situados no interior das metrópoles já não comportam as soluções de tipo remoção-reassentamento tão utilizadas nas décadas de 1960 e 1970. Tanto os relatórios da ONU-Habitat como o texto «Planeta Favela», convergem para um ponto que antecipa o preocupante futuro urbano. Davis sintetiza num parágrafo um duro balanço no qual se insere a cidade do futuro:

Assim, as cidades do futuro, em vez de feitas de vidro e aço, como fora previsto por gerações anteriores de urbanistas, serão construídas em grande parte de tijolo aparente, palha, plástico reciclado, blocos de cimento e restos de madeira. 
Em vez das cidades de luz arrojando-se aos céus, boa parte do mundo urbano do século XXI instala-se na miséria, cercada de poluição, excrementos e deterioração. (Davis, 2006, p.28-29)

Impossível deixar de associar esta antevisão da cidade do futuro, feita pelo sociólogo americano a partir de dados precisos da realidade urbana do século XXI, com Coketown - o paraíso paleotécnico - descrito por Lewis Munford enquanto lugar da classe trabalhadora das últimas décadas do século XIX. Seu ponto de vista ao descrever as condições materiais das nascentes cidades industriais, sobretudo aquelas situadas nos países pioneiros da industrialização, continha aspectos presentes nos relatórios da ONU-Habitat dos anos 2000 e nas recentes análises de Mike Davis:

Como a dar testemunho da imensa produtividade da máquina, os montes de lixo e detritos alcançavam proporções de montanha, ao passo que os seres humanos, cujo trabalho tornava possíveis aqueles feitos, eram mutilados e mortos quase tão depressa quanto teriam sido num campo de batalha. A nova cidade industrial tinha muitas lições a ensinar; mas, para o urbanista, a sua principal lição dizia respeito ao que se deveria evitar. Reagindo contra os descaminhos do industrialismo, os artistas e reformadores do século XIX chegaram finalmente a uma concepção melhor das necessidades humanas e das possibilidades urbanas. No fim, a doença estimulou a formação dos anticorpos necessários para vencê-la. (Mumford, 1998, p. 433)

Simultaneamente à expansão e consolidação da precariedade das condições urbanas impostas pela localização dos pobres nas cidades e metrópoles, associaram-se ao longo das últimas três décadas do século xx, questões decorrentes da favelização dos ambientes urbanos. Pois, se por um lado é preciso reconhecer que a construção da cidade do futuro deveria se centrar na eliminação dos núcleos urbanos ocupados pelos mais pobres -- as favelas e seus congêneres -- por outro, novas questões urbanas oriundas das próprias características do processo de urbanização acelerada, passaram a exigir muita reflexão e, sobretudo, ação. O léxico que identificava os novos temas urbanos e suas respectivas demandas é tão amplo e variado quanto a própria diversidade das cidades e metrópoles em todo mundo. Através de uma semântica que traduz compromissos com um futuro menos sombrios, temos a partir da década de 1980 convivido com abordagens que apontam saídas pragmáticas 
e temáticas para os problemas das cidades. Estas são, quase sempre, baseadas em análises específicas com encaminhamentos metodológicos voltados para ações unidimensionais. A lista é enorme e não cessa de ampliar-se: «cidade inteligente, cidade sustentável, cidade digital, cidade inovativa, cidade verde ou eco-cidade, cidade habitável (liveable city), cidade provisional, cidade compacta», etc. Um ponto final é colocado nesta enumeração com a certeza de que a lista está obviamente incompleta e, que enquanto esse artigo é escrito uma nova categoria já estará sendo gestada.

No entanto, é preciso fazer uma ressalva, a enumeração acima não representa, em si mesma, uma crítica. Trata-se na verdade de indicar as tentativas de encontrar um tema que sintetize o conjunto das questões urbanas. A própria disciplina - o urbanismo - que possui seus próprios métodos de análise, seu vocabulário específico e suas formas de proposição, ao eleger cada um destes qualificativos acaba por dar legitimidade a alguns dos temas com a intenção de responder às demandas do amplo quadro dos atuais problemas urbanos. Com isso, acaba por eleger de forma isolada uma questão para presidir as estratégias e as ações que deverão conduzir a uma nova e mais qualificada situação urbana. Mas embora cada um deles possa ser visto como valido e estimável, coloca o risco de assumir a cidade como um ente simplificado, ou monotemático. E, assim levar o conceito de cidade com o qual trabalhamos a perder a força que reside precisamente na sua inerente e incontornável complexidade.

Ficou evidente, sobretudo a partir da década de 1980 que as caracterizações do processo de urbanização contemporâneo que até então soavam meramente retóricas, estavam muito atuantes e produzindo transformações diretas na organização das cidades. Uma máxima sintetizou as observações «a cidade está em toda parte». A sua interpretação levou o planejamento urbano, assim como o próprio urbanismo a partir para antigas práticas voltadas a restringir e cercear o processo de urbanização fora de controle. E, uma vez mais, as iniciativas do planejamento e do urbanismo se mostraram inócuas. O processo de urbanização se mostrou incólume aos instrumentos de controle utilizados.

Ademais, uma ampla teorização acompanhada de conjunto de conceitos foram indicando predicados específicos que o processo de urbanização estava adquirindo em todo o mundo. Designações como — difuso, dissipado, dis- 
perso, extensivo, fragmentado, poroso, dentre outros, inundaram os encontros e livros acadêmicos. Destas discussões um aspecto destacou-se: o atual padrão de urbanização mostrou-se efetivamente original, distinto de formas anteriores de crescimento urbano. As pesquisas elaboradas por diversas áreas dos chamados estudos urbanos, confirmaram a existência de um processo mais extenso e intenso, além de bastante disruptivo (Ramos, 2004).

Analisado sempre a partir de si mesmo, o processo de urbanização permaneceu ao longo do século xx um fenômeno localizado para além da própria cidade, algo que ocorria a partir de seus limites, a partir dos seus subúrbios e, mais tarde, de suas periferias. Porém os atuais traços do novo padrão já não permitem compreende-lo de forma isolada. Os termos que o descrevem, como visto acima, não deixam dúvida, pois cada um deles pontua aspectos específicos, resultantes de parâmetros de análise com origens em campos disciplinares distintos, com ênfases em aspectos selecionados de maneira parcial. E, é importante sublinhar para atender alguns objetivos deste artigo, que o processo de urbanização que assimilou continuamente antigos núcleos urbanos a partir de um central mais desenvolvido - a denominada conurbação - gerando os processos de metropolização, na etapa anterior do capitalismo industrial, deixou de presidir o processo de crescimento urbano atual. O traço a ser destacado agora é que aprisionada dentro dos enormes territórios em processo de urbanização ilimitada, a cidade vai ficando submersa, em todas as suas escalas, de forma transversal e centrípeta. A forma centrípeta do atual processo de urbanização, difere de maneira radical da conurbação, que foi essencialmente centrífugo.

Os conceitos mais influentes que visam sintetizar este cenário, abarcando a cidade, são inexoráveis quando afirmam que estamos diante da post-cidade. No seu livro Ladders, de 1996 o arquiteto Albert Pope designa o resultado do atual estágio do processo como indiviso, e o denomina - superurbano (Pope, 1996). Seus argumentos buscam situar a urbanização e a cidade no interior de um único processo, isto é, no interior de um movimento centrípeto e fechado, de fora para dentro no qual a urbanização «abocanha» a cidade consolidada, desorganiza a sua estrutura ( $g r i d$ ) funcional, seus espaços públicos, em suma, tudo que a distinguia do que lhe era externo, produzindo uma mancha urbana integral (Pope, 1996, p. 95-97). 
A constatação da radicalidade do novo processo de urbanização exigiu que o urbanismo e o planejamento urbano enfrentassem a situação com novas estratégias, tanto teóricas como pragmáticas. A empreitada deu inicio a uma grande reflexão teórica e repleta de imagens reveladoras. É impossível estabelecer aqui um quadro detalhado das inúmeras posições teóricas, mas de uma maneira geral estão de um lado aquelas que mantém a visão radical do processo, insistindo na presença da post-cidade e, do outro, aquelas que abrem brechas no cipoal do território buscando descobrir oportunidades para propor ações utilizando instrumentos mais operacionais. Um aspecto que deve ser sublinhado, é que à medida que o próprio processo de urbanização, passa a ser visto de um ângulo mais complexo e dinâmico, com os geógrafos e sociólogos assumindo um papel de destaque, algumas possibilidades para planos e projetos urbanos foram surgindo.

\section{Condições para um possível novo urbanismo}

Aqui é momento de recuperar duas questões conceituais dos anos 70 já abordadas acima: a primeira por Manfredo Tafuri e a segunda por Nuno Portas. Considerando que desde então as cidades viveram uma imensa revolução na sua organização, tendo ocorrido uma transformação tão radical nos meios de produção, com a cidade ocupando um lugar decisivo e ativo nesse processo, é compreensível que todos os conceitos e análises anteriores tenham perdido sua força interpretativa e propositiva. No entanto, observados de uma perspectiva de continuidade do modo produtivo capitalista que hoje vive uma nova etapa, veremos que os temas abordados pelos dois autores possuem atributos atemporais e seguem sendo perfeitamente atuais. Mesmo reconhecendo que ambos estavam diante de uma conjuntura histórica, econômica, social e urbana ainda muito longe da atual e terrível post-cidade, seus argumentos ainda ecoam com força e fazem sentido.

No capítulo final de «Projeto e Utopia» Tafuri faz uma advertência a todos que pensam poder «esquivar-se pela tangente» ao enfrentar a situação do urbanismo no momento histórico sobre o qual seu livro se debruça. Sua advertência serviu, é claro, para os profissionais cujas atividades estavam nos anos 70 situados no campo do urbanismo e do planejamento urbano, tanto 
através de construções teóricas como nas frentes propositivas. E, pensando hoje nas questões que estavam presentes naquele momento é possível reconhecer a validade dos argumentos para a realidade atual. Basta lembrar que para Tafuri nos anos 60 ainda «havia um compasso de espera à reorganização capitalista». Tal espera encaminhou-se para um desfecho e o processo de reorganização do modo de produção foi reconhecido desde a década de 1980 com a conclusão do processo de globalização econômica e, mais recentemente, com a presença da Quarta Revolução Industrial.

Portanto, muitos pontos levantados por Tafuri, embora tenham se alterado e não sejam mais exatamente os mesmos, ainda guardam significado claro no presente. Como por exemplo, aceitar a permanência da dificuldade de remover desequilíbrios no âmbito da ocupação do território urbanizado. Essa foi uma observação feita diante da cidade industrial dos anos 60 que se mostra inteiramente válida diante da cidade pós-industrial deste inicio do século XXI. Outro ponto importante diz respeito à critica ao «ordenamento urbano», obcecadamente procurado ao longo de quatro décadas por arquitetos e planejadores, avaliado por Tafuri, como não sendo um método alternativo, certo ou errado, mas apenas como um método anacrônico.

A superação desta «anacrônica ideologia disciplinar» permanece como uma tarefa para o desenvolvimento urbano que emana dos órgãos públicos e de grande parte do contexto acadêmico visando a construção da cidade do futuro. E, esse é justamente o ponto de convergência entre o pensamento crítico de Tafuri e o método de intervenção na cidade existente, elaborado por Nuno Portas. Para quem intervir na cidade existente implica considerar um conjunto de programas e projetos públicos ou de iniciativas autônomas, que incidam sobre os tecidos urbanizados dos aglomerados, sejam eles antigos ou relativamente recentes, tendo em vista diversos objetivos, desde a sua reestruturação ou revitalização funcional, almejando sempre a sua reapropriação, econômica, social e cultural.

Para tanto é necessário conhecer as dinâmicas urbanas presentes nos trechos de cidade nos quais há um objetivo de intervir. A estratégia nesse caso é substituir a proposta e o controle regido baseado em premissas fixadas de forma antecipada, por um conjunto de ações de planejamento articuladas de forma clara aos projetos urbanos. $\mathrm{O}$ fundamento central desta abordagem 
alternativa é permutar «planos que regulam a ação" por "planos de ação conduzidos por projetos» (Meyer, Grostein and Biderman, 2004, p. 31) . Sendo que tais proposições não poderão avançar sem a contribuição de análises transdisciplinares capazes de enfrentar a complexidade urbana que está instalada de forma nova, tanto no que diz respeito aos seus atributos espaciais, como pelas escalas que a mancha urbanizada está adquirindo em ritmo continuo e veloz.

Portanto, acompanhar e equacionar encaminhamentos para as permanentes mudanças no interior dessas dinâmicas de transformação é uma postura promissora diante das atuais aspirações, compromissos e possibilidades do urbanismo e do planejamento urbano. Contribuiu também para realização desta meta o arquiteto catalão Joaquin Sabaté ao introduzir uma variável indispensável quando afirma que «a crise do modelo racional-abrangente supõe a expulsão do paraíso artificial do planejamento urbano e territorial monolítico e confiante». E, acrescenta: «nossa época se caracteriza pela incerteza, a interdependência e as aceleradas transformações» (Sabaté, 2007).

A partir de premissas e conceitos bastante semelhantes, uma síntese é expressa de forma muito precisa pelo arquiteto Rem Koolhaas:

Se houver um «novo urbanismo», ele não se baseará em fantasias gêmeas de ordem e onipotência; terá que conviver com o embaraço da incerteza; deixará de se preocupar com o arranjo de objetos mais ou menos permanentes, em favor da irrigação de territórios com potencial; deixará de visar configurações estáveis, em favor da criação de campos com potencialidade de acomodar processos que se recusam a ser cristalizados em forma definitiva; não será mais uma definição minuciosa, a imposição de limites, em favor da expansão de noções, a negação de limites, não a separação e identificação de entidades, mas a descoberta de híbridos inomináveis; deixará de ser obcecado pela cidade, em favor da manipulação da infraestrutura para infinitas intensificações e diversificações, atalhos e redistribuições - a reinvenção do espaço psicológico. Como o urbano é hoje difuso, o urbanismo nunca mais será apenas sobre o novo apenas sobre o «mais» e o «modificado». Não será sobre o civilizado, mas sobre o subdesenvolvimento (Koolhas, Mau, Sigler and Werlemann, 1995, p. 959-971).

Embora inicie sua reflexão por um incerto e condicional se, Koolhaas percorre neste límpido parágrafo um arco de posturas que vão desde os onipotentes imperativos de uma ordem urbana inacessível, até o convívio correto 
com a incerteza, rumo ao que ele acredita repousar as chances de criação de um novo urbanismo. Propõe deixar de lado os arranjos definitivos para almejar acompanhar a constante mudança das necessidades da vida urbana contemporânea. Algumas expressões utilizadas por Koolhaas neste seu manifesto tem a força de partidos de projeto para o urbanismo da cidade do futuro, como por exemplo: «irrigar territórios com potencial». A aceitação de propor apenas o «mais» e o «modificado» coloca o urbanismo numa posição realista e mais eficaz, nem utópica nem distópica.

Diante destas análises tão inspiradoras, mas ao mesmo tempo tentando evitar, ainda uma vez, «fugir pela tangente», o urbanismo e o planejamento urbano, ambos comprometidos com a efetividade de uma ação que conte com o projeto como instrumento de trabalho, precisam ainda construir caminhos efetivos para a sua atividade reflexiva, propositiva e projetual.

De um ponto de vista muito arguto o catalão Manuel de Solà-Morales atende essa demanda quando chama a atenção para as peculiaridades do padrão de expansão urbana, metaforicamente denominado mancha de óleo. Visto como ruinoso para as cidades, este padrão de urbanização sem forma e, em princípio sem nexo no seu modo de expansão, ganhou na sua análise um conteúdo interpretativo e operacional, para as ações de planejamento e de propostas urbanísticas. Apesar de seu caráter polêmico, sobretudo por ter focado num aspecto reconhecidamente nocivo da urbanização, a mancha de óleo, sua reflexão e argumentos ganham grande importância.

É a partir das clássicas críticas ao modelo de expansão em mancha de óleo que se assentam dois aspectos principais da proposta de Solà Morales: a impossibilidade de estabelecer qualquer forma de controle tendo em vista o caráter aleatório desse tipo de crescimento urbano e, como desdobramento, a total impossibilidade de encontrar critérios racionais para balizar a instalação de infraestruturas urbanas. Para ele a possibilidade de preservação da contiguidade do tecido urbano só ocorrerá se nos desfizermos de regras e normas de uso e ocupação do solo que favorecem cisões entre o tecido consolidado e as novas funções e ocupações dos territórios em processo de urbanização. Ou seja, para garantir e não apenas impedir, através de normas e legislação existente a justaposição de trechos urbanos regidos por critérios de eficiência urbana, em todos os sentidos - do físico-territorial ao funcional e espacial -, 
as regras precisam ser passíveis de flexibilização, de interações com o território, de ajustes precisos ditados por situações específicas. Vale lembrar aqui as teses discutidas acima que conduzem ao funesto padrão proposto por Albert Pope, o superurbano. Solà Morales abre nova perspectiva, menos conformista, tanto do ponto de vista metodológico como propositivo: a demarcação de trechos urbanos que através de uma análise funcional, territorial e espacial ganhem a condição de zonas urbanizáveis. Para ele o crescimento urbano analisado a partir desse registro assumirá um papel de resposta às formas de expansão que geraram e ainda estão gerando dispersão urbana e a erosão da cidade consolidada. Principalmente aquelas propiciadas pelo próprio processo de urbanização, definido pela demarcação de zonas urbanizáveis. $\mathrm{O}$ urbanista não vê nada de aleatório no contínuo processo de agregação de novos trechos urbanos, característico do padrão mancha de óleo:

[...] quando se trata de um processo de urbanização intenso e extenso, é necessário tirar partido do papel positivo que podem desempenhar as pequenas peças urbanas (el grano pequeño) como elementos articuladores de territórios que tendem a ser ilimitados e, sobretudo amorfos. (Solá-Morales, 2008, p. 162)

Os aspectos centrais da urbanização contemporânea na sua relação frente à cidade, tais como a topografia, os padrões de propriedade fundiária, as normas urbanísticas e, sobretudo, as questões ambientais que podem funcionar como parâmetros para encaminhar uma urbanização menos predatória, podem estar dentro de peças urbanas passíveis de promover algum equilíbrio, mesmo que transitórios. Não cabe neste artigo aprofundar esta questão, no entanto, vale lembrar que a argumentação sobre o processo de urbanização contemporâneo tal como o faz Solà-Morales tem fundamento e propósito quando se analisa a urbanização contemporânea. Sua defesa de crescimento urbano contíguo visa acentuar o aspecto disfuncional que assumem os imensos equipamentos comerciais, os grandes conjuntos habitacionais, os condomínios residenciais fechados, que se localizam de forma autônoma e isolada em territórios demarcados por zoneamentos funcionais, ocupando grandes glebas e promovendo descontinuidades físico-espaciais.

Todas as áreas do conhecimento e técnicas relacionadas às questões relativas ao funcionamento das cidades, metrópoles e macrometrópoles tem reiterado a tendência de permanência dos processos de formação de territórios 
cada vez mais extensos e complexos. Métodos, vistos como estratégicos, apresentados como possíveis refreadores dos processos de urbanização ilimitada, tem frustrado as metas e as expectativas de seus formuladores. Portanto, se o prenúncio de uma urbanização tão continua e ampla já é tão claro, a atitude mais estratégica é buscar formas de reduzir os impactos de sua consumação sobre os territórios consolidados nos quais, com certo esforço metodológico, podemos identificar a cidade; esteja ela contida, numa metrópole, numa megalópole ou numa macrometrópole. O importante e necessário é «qualificar os territórios da urbanização extensiva ao invés de buscar apenas fórmulas para conter sua difusão sem limite (Domingues, 2008)». Esta é, provavelmente, uma postura a ser examinada e considerada para que possamos verificar as reais possibilidades do «mais» e do «modificado» que propõe Koolhaas. A partir dela, algumas frentes de ação se abrem e podem ser capturadas pelo planejamento urbano, projetadas pelo urbanismo, estabelecidas por políticas urbanas conduzidas pelo poder público, que terão por objetivo preservar nosso conceito de cidade.

\section{Referências}

Argan, G. C. (1992). História da arte como história da cidade (P.L.Cabra, Trans.). São Paulo: Martins Fontes.

DAvis, M. (2006). Planeta favela (Maricato, E., Cypriano, A., \& Medina, B., Trans.). São Paulo: Boitempo.

Domingues, A. (2008, May). Urbanização extensiva - uma nova escala para o planejamento. Paper presented at CITTA 1st Annual Conference on Planning Research, FEUP Porto.

DPU-UCL \& UN Programme of Human Settlements. (2003). Understanding slums Case studies for the global report on human settlements 2003. London: Development Planning Unit UCL

Jonas, A. E. G., \& WiLson, D. (1999). The urban growth machine: critical perspectives, two decades later. Albany: State University of New York Press.

KoolhaAs, R., Mau, B., Sigler, J., Werlemann, H. (1995). What Ever Happened to Urbanism? In Small, medium, large, extra-large: Office for Metropolitan Architecture. New York: Monacelli Press. 
Lefebvre, H. (1999). A revolução urbana (Martins, S., \& Andrade, M. M. de., Trans.). Belo Horizonte: Editora UFMG.

Molotch, H. (1976). The City as a Growth Machine: Toward a Political Economy of Place. American Journal of Sociology, 82(2), 309-332. doi: $10.1086 / 226311$

Meyer, R. M. P., Grostein, M. D. \& Biderman, C. (2004). São Paulo Metrópole. São Paulo: EDUSP.

Mumford, L. (1998). A cidade na história: suas origens, transformações e perspectivas. São Paulo: Martins Fontes.

Perec, G.(2000). Espèces d'espaces. Paris: Ed. Galilée

Pope, A. (1996). Ladders - Architecture at rice 34. New York, NY: Princeton Architectural Press.

Portas, N. (1969). A cidade como arquitectura: apontamentos de método e crítica. Lisboa: Livros Horizonte.

Ramos, À. M. (2004). Lo urbano en 20 autores contemporáneos. Barcelona: Universitat Politecnica de Catalunya (Iniciativa Digital Politecnica).

SABate Bel, J. (2007). Proyectar el territorio en tiempos de incertidumbre : Camp de Tarragona : proyectos para una nueva configuración territorial. Barcelona: Universitat Politècnica de Catalunya.

SolÀ-Morales, M. DE (2008). De cosas urbanas. Barcelona: Gustavo Gili.

TAfuri, M. (1985). Projecto e utopia. Barcarena: Editorial Presença.

Un Human Settlements Programme (2003). The Challenge of Slums: Global Report on Human Settlements 2003. London: Routledge

Williams, R. (1975). The country and the city. London: Paladin.

Wright, F.L. (1970). The living city. New York, London: Horizon Press. 